\title{
Adverse events of fecal microbiota transplantation: a meta- analysis of high-quality studies
}

\author{
Lamprinos Michailidis, Alden C. Currier, Michelle Le, Deborah R. Flomenhoft
}

University of Kentucky College of Medicine, Lexington, KY, USA

\section{Abstract}

\section{Introduction}

Fecalmicrobiotatransplantation(FMT) is theadministration of a solution of fecal matter from a donor into the intestinal tract of a recipient in order to directly change the recipient's gut microbial composition and confer a health benefit [1]. FMT has a long history, as it was first used to treat gastrointestinal (GI) disorders in the fourth century by a Chinese Doctor named Ge Hong [2]. It was used in veterinary medicine as early as 1973

Department of Digestive Diseases and Nutrition, University of Kentucky College of Medicine, Lexington, KY, USA

Conflict of Interest: None

Correspondence to: Lamprinos Michailidis, MD, University of Kentucky College of Medicine 800 Rose Street Room MN649, Lexington, KY 40536, USA, e-mail: lamich@gmail.com

Received 21 September 2020; accepted 8 March 2021; published online 2 July 2021

DOI: https://doi.org/10.20524/aog.2021.0655 to reduce salmonella carriage in poultry [3]. In the modern era, Eiseman [4] first reported the use of FMT enemas in humans in 1958 to treat pseudomembranous colitis (a form of Clostridium difficile [C. difficile] infection); it was next reported in 1984 [5] and its application has expanded since. During the past decade, research interest in FMT has increased greatly. In 2009, there were 2 articles published about FMT in the Medline database, whereas in 2019 a PubMed search returned 600 articles. The most established indication for FMT is recurrent C. difficile infection (rCDI), for which it has been extensively studied and demonstrated good efficacy [1,6-10], cost effectiveness [11-13], and safety [14-16]. FMT has been studied in inflammatory bowel disease with mixed results [9,17-22], as well as a plethora of other diseases of the GI tract: irritable bowel syndrome [23-26], obesity [27], insulin resistance [28], multi drug-resistant organism (MDRO) decolonization [29], constipation [30], hepatic encephalopathy [31], pouchitis [32], primary sclerosing cholangitis [33], and checkpoint inhibitorinduced colitis [34]. Furthermore, recent insights into the microbiome and gut-brain axis have led to small reports of 
FMT use in other neuropsychiatric, autoimmune and metabolic disease states, such as anorexia [35,36], multiple sclerosis [37], autism [38], sepsis [39], and others [40]. As of July 2020, there are over 300 clinical trials of FMT registered with the National Institutes of Health, indicating the worldwide enthusiasm with FMT and hinting at hopes it will be a "panacea" of sorts.

This enthusiasm has been tempered by safety concerns surrounding the use of FMT $[127,128]$. The treatment appears to be fairly safe in the short term, but serious adverse events (SAE) have been described, such as aspiration pneumonia, bacteremia, and death [21,41-43], and the longterm safety profile remains unclear. In 2019, the Food and Drug Administration (FDA) issued a safety communication regarding extended-spectrum $\beta$-lactamase producing Escherichia coli (E. coli) infections transmitted from FMT that resulted in the death of one patient [44]. The complex nature of the intestinal microbiome introduces a variability in FMT, unlike any other widespread treatment, as every treatment is different. Furthermore, published studies vary in their quality, methodology, donor selection, mode of FMT delivery and follow up. Thus, it is unclear what the rates and severity of adverse events (AE) are, or whether there are any risk factors for the occurrence of such events. We decided to perform a meta-analysis of rigorously selected, high-quality, randomized controlled trials (RCTs) of FMT to obtain reasonable estimates of that risk.

\section{Materials and methods}

\section{Literature search}

A systematic literature search was performed in August 2019 of the MEDLINE (PubMed) and Science direct databases to identify studies for inclusion. The exact search terms can be seen in Appendix 1. The search was performed within the title, abstract and key words. The references of relevant articles were reviewed and additional abstracts were added. The search strategy is detailed in Fig. 1. After removal of duplicates, 334 original articles were screened further.

\section{Study selection and exclusion criteria}

Two reviewers (LM \& CC) independently searched the literature and identified studies for inclusion. Disagreements were resolved by consensus between the 2 authors and discussion with a senior author (DF) when necessary. To minimize publication bias, case reports or case series with fewer than $20(\mathrm{n}<20)$ were excluded from analysis. Other exclusion criteria were: article published in language other than English; abstract form only with no full text available; review articles; and series including a pediatric patient population or non-relevant to the research question. In addition, studies that did not report AE clearly, or did not report the incidence of $\mathrm{AE}$ as a percentage of the patients who underwent FMT, were excluded. For example, if a study only reported AE as a percentage of the number of FMTs performed, and patients could have received more than a single FMT, the study was excluded so as to not interfere with the analysis. After these criteria were applied, 60 studies were selected for preliminary analysis.

\section{Data extraction and quality assessment}

Data included the following predefined characteristics and variables: first author last name, year of publication, study design, patient demographics (mean age, sex), followup duration in weeks, number of patients, number of FMTs performed, indication, delivery method, rate of $\mathrm{AE}$, rate of $\mathrm{SAE}$. We recorded rates of all $\mathrm{AE}$ as they were reported by authors, based on their definitions of what constitutes an AE. We also noted whether the authors used the Common Terminology Criteria for Adverse Events (CTCAE) [45] or some other standardized methodology in reporting AE. It should be noted that there was significant heterogeneity in $\mathrm{AE}$ reporting. Reported rates ranged widely, from 5.5-90.5\% of patients experiencing at least one AE.

The quality of studies was assessed using the revised Cochrane risk-of-bias tool for randomized trials, version 2 [46]. After quality assessment, we selected for final analysis 9 studies that had a prospective, randomized methodology, a followup period of at least 6 weeks, and a low risk of bias on quality assessment.

\section{Heterogeneity testing}

Assessment of heterogeneity was performed by calculating Cochran's Q statistic, $\tau^{2}$ (estimates the between-study variance) and $I^{2}$ (quantifies the degree of heterogeneity) with P-values $<0.1$ considered statistically significant $[47,48]$. Publication bias was assessed using a funnel plot. Heterogeneity was assessed for each individual outcome (total AE and SAE) and during subgroup analysis. Irrespective of heterogeneity, the random-effects model was used to calculate pooled effects for each outcome and subgroup.

\section{Outcomes measured}

The outcomes measured were: 1. the total rate of $\mathrm{AE}$ observed during the follow-up period; 2 . the total rate of SAE observed during the follow-up period; and 3. the risk factors associated with AE development, using subgroup and metaregression analyses.

\section{Statistical analysis}

The final analysis included the 9 highest quality studies. The total number of patients who received FMT and the 


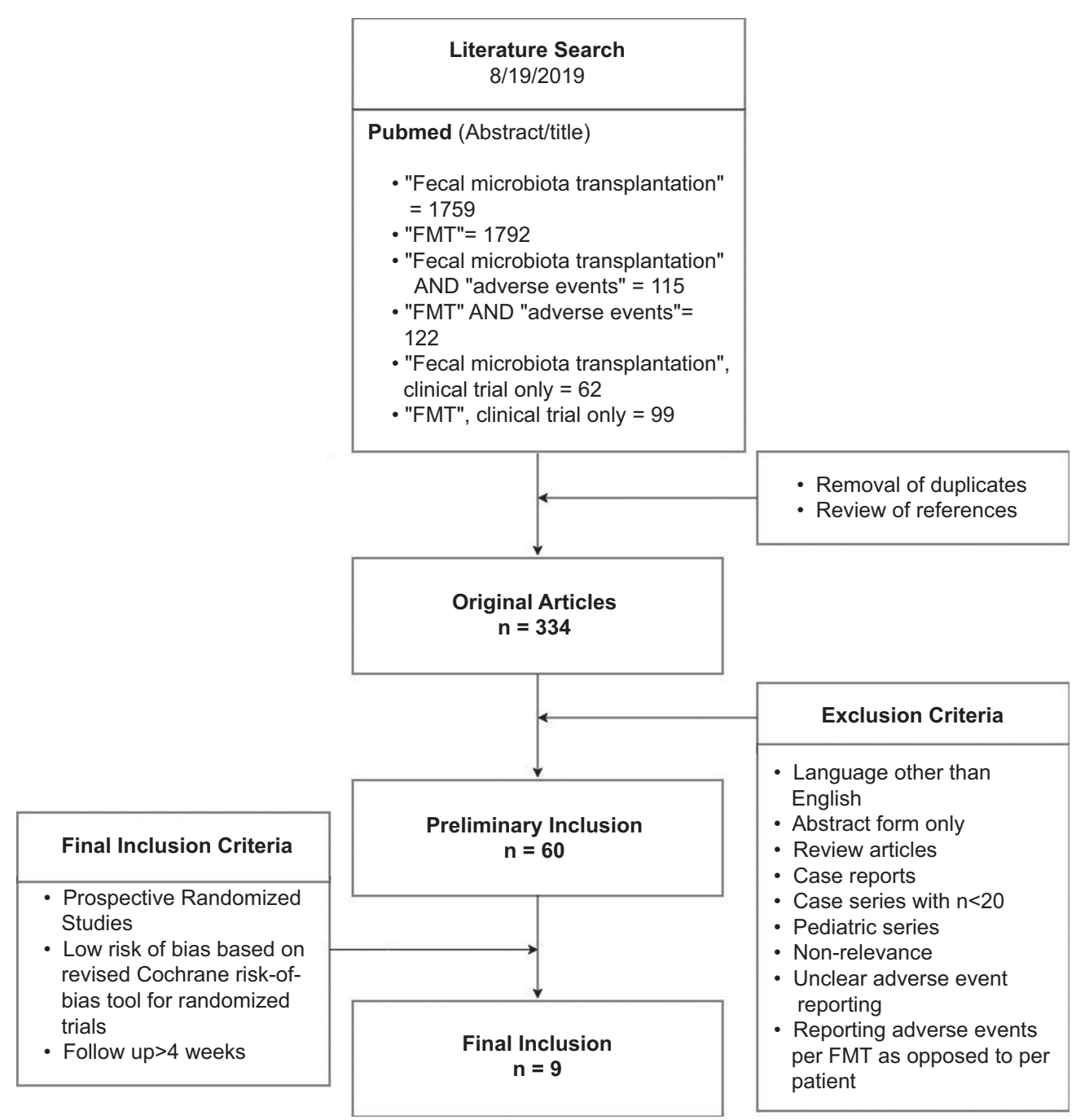

Figure 1 Literature search strategy

total number of AE (as defined by authors) observed during the follow-up period were noted for each study. The same was done for SAE, again as per author definition. Only the patients for whom final outcomes were reported were included in the analysis. Patients lost to follow up were not included. Variables of interest were treated as continuous variables with means and variations [49]. We conducted a meta-regression analysis on the 9 highest quality studies with regard to delivery method for both outcomes. Under the random-effects model, the Q statistic, $\tau^{2}$ and $I^{2}$ were calculated to test the model and attempt to explain the variance between studies. The $\mathrm{R}^{2}$, the proportion of variance explained by the covariates, was also calculated. The correlation of each individual covariate with $\mathrm{AE}$ rates was assessed for statistical significance under both models. Scatterplots were generated for all covariates under both models. The models were underpowered because of missing data in the case of SAE. The lower GI delivery group was used as a reference group, and studies with mixed methods of FMT delivery were excluded from this particular analysis as potential confounders. In an attempt to determine certain subgroups that might experience a higher SAE rate and identify potential risk factors, we decided to expand the analysis to the 60 original studies. We calculated the AE and SAE rates of different subgroups based on delivery method and indication. Finally, we performed a meta-regression analysis to identify risk factors for $\mathrm{AE}$ development.

The optimal regression model included the following covariates: delivery method, follow up in weeks, and percentage of female patients. Several studies reported median ages and/or median durations of follow up; for these studies, means and variances were recalculated, using a formula previously described by Hozo et al [49], and mean values were included in the analysis. Again, the lower GI delivery group was used a reference group, and studies with mixed methods of FMT delivery were excluded from this particular analysis as potential confounders. A total of 26 studies with fully available covariates were included in this additional analysis. Statistical analyses were performed using Comprehensive Meta-Analysis software, version 3.3.070 (Biostat, Englewood, NJ 07631, USA). 


\section{Results}

\section{Descriptive assessment of included studies}

Our initial literature search yielded 3949 articles. After removal of duplicates and review of references, 334 articles were selected and reviewed further. Of these, 60 studies were selected for preliminary inclusion after application of the exclusion criteria. We further selected for final inclusion 9 prospective, randomized studies $[9,17,22,23,50-54]$ that had a low risk of bias based on our quality assessment using the revised Cochrane risk-of-bias tool for randomized trials.

The studies finally included were published between 2014 and 2019. All studies were prospective and controlled, and 5 of the 9 were also blinded $[9,17,22,23,52]$. Five of the 9 studies were performed in Europe [9,23,50-52], one in Australia [22], 2 in Canada [17,53], and one in the United States [54]. The studies described a total of 756 FMT procedures performed in 388 patients. The mean age of the participants was $50.4 \pm 12$ years and $70 \pm 11 \%$ were female. Follow up had a mean duration of $17 \pm 14$ weeks and ranged from 6 to 52 weeks. Indications were: rCDI in 3 studies $[51,53,54]$, ulcerative colitis (UC) in 3 studies $[9,17,22]$, irritable bowel syndrome (IBS) in 2 studies [23,52], and MDRO colonization in one study [50]. FMT delivery methods included: colonoscopy [22,23], enema [17], nasoduodenal tube [9], capsules [52], and various methods in 4 of the studies $[50,51,53,54]$. All of the patients included in the analysis received heterologous, or donor-stool FMT. One of the studies included autologous FMT cases as the control arm [9]. We decided not to include these patients in the final analysis as autologous FMT may have a different AE profile than heterologous FMT [55].

All studies reported $\mathrm{AE}$ and $\mathrm{SAE}$ incidence rates as percentages of the patients that received FMT. Only 2 of the authors used published guidelines on defining and reporting
AE. Hvas et al used guidelines published by the European Commission [56]. Youngster et al used a modification of the CTCAE [57]. Certain authors specified whether the AE were thought to be related, possibly related or unrelated to the FMT procedure. If an $\mathrm{AE}$ was deemed to be unrelated by the authors, it was not included in the analysis. That was also the case for the analysis of the 60 studies included in the preliminary selection. A detailed description of the included studies can be seen in Table 1.

\section{Total AE rate}

One of the primary outcomes was to calculate the total rate of AE observed after FMT. A total of 124 of the 388 patients who received FMT experienced at least one AE during follow up. The pooled rate of $\mathrm{AE}$ was calculated at $39.3 \%(95 \%$ confidence interval [CI] 0.19-0.642; 2-sided $\mathrm{P}=0.4$ ). A forest plot of pooled AE rates can be seen in Fig. 2. The vast majority of $\mathrm{AE}$ were mild. The most common $\mathrm{AE}$ in every study were: bloating $[9,51,54]$, abdominal pain $[23,53]$, worsening of colitis [17,22], nausea/vomiting [52], and diarrhea [50]. Overall, the most common AE was abdominal pain, reported in $5.9 \%$ of the patients, followed by diarrhea, reported in $5.2 \%$ of the patients. A detailed description of all AE can be seen in Table 2 .

\section{SAE}

Another primary outcome measure was the rate of SAE. Serious adverse drug experiences, as defined by US Federal Code [58], are those that result in death, a life-threatening adverse drug experience, inpatient hospitalization or prolongation of existing hospitalization, a persistent or significant disability/incapacity, or a congenital anomaly/birth defect. We analyzed SAE as they were reported by the authors. A total of 11 of the 388 patients experienced at least one SAE

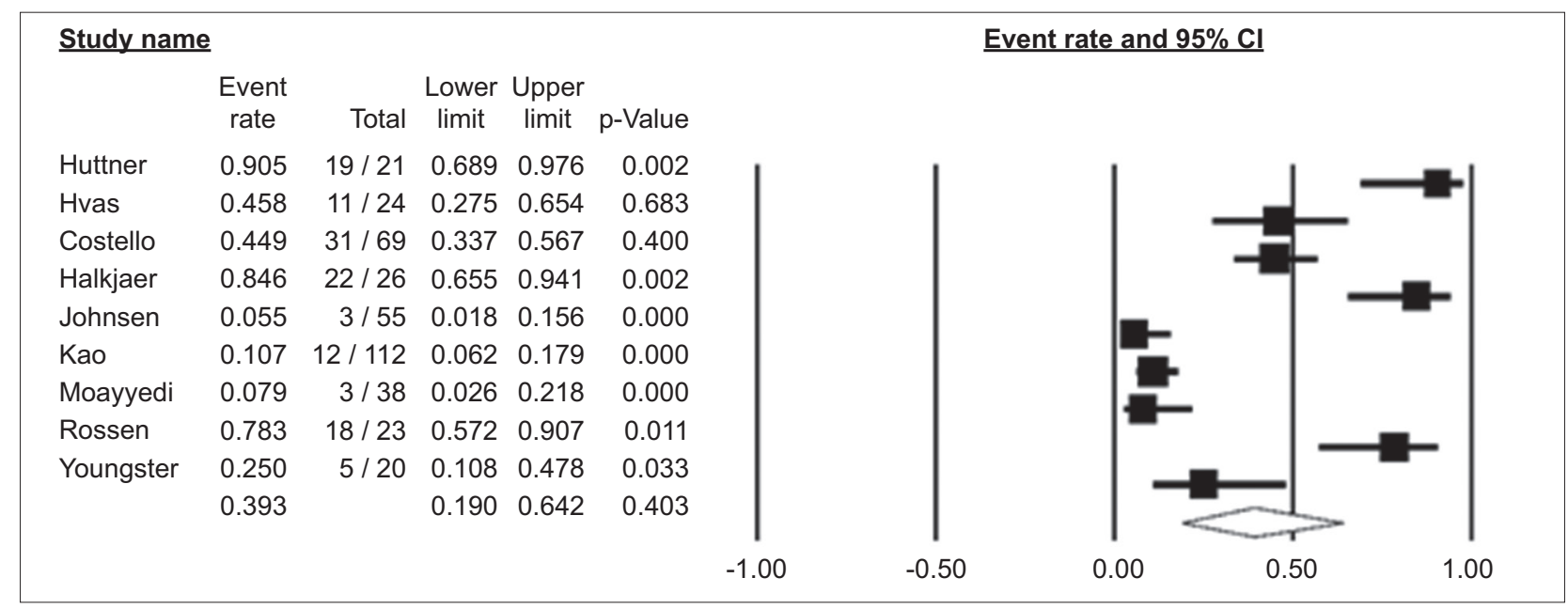

Figure 2 Forest plot of total adverse event rate CI, confidence interval 
Table 1 Characteristics of the included studies

\begin{tabular}{|c|c|c|c|c|c|c|c|c|c|}
\hline $\begin{array}{l}\text { First author, } \\
\text { year [Ref.] }\end{array}$ & Indication & $\begin{array}{l}\text { Number } \\
\text { of } \\
\text { patients }\end{array}$ & $\begin{array}{c}\text { Average } \\
\text { age }\end{array}$ & $\begin{array}{l}\text { Percentage } \\
\text { female sex }\end{array}$ & $\begin{array}{c}\begin{array}{c}\text { Number } \\
\text { of } \\
\text { patients }\end{array} \\
\text { with AE }\end{array}$ & $\begin{array}{l}\text { Most } \\
\text { common } \\
\mathrm{AE}\end{array}$ & SAE & $\begin{array}{l}\text { Routes of } \\
\text { infusion }\end{array}$ & $\begin{array}{l}\text { Average } \\
\text { follow- } \\
\text { up time } \\
\text { (weeks) }\end{array}$ \\
\hline $\begin{array}{l}\text { Huttner, } \\
2019[50]\end{array}$ & $\begin{array}{l}\text { MDRO } \\
\text { colonization }\end{array}$ & 21 & 70 & $54.6 \%$ & 19 & $\begin{array}{l}\text { Diarrhea } \\
(57 \%)\end{array}$ & $\begin{array}{l}\text { Hepatic } \\
\text { encephalopathy } \\
(4.8 \%)\end{array}$ & $\begin{array}{l}\text { Colonoscopy } \\
\text { \& Capsule }\end{array}$ & 6 \\
\hline $\begin{array}{l}\text { Hvas, } \\
2019[51]\end{array}$ & rCDI & 24 & 68 & $83.3 \%$ & 11 & $\begin{array}{l}\text { Bloating } \\
(21 \%)\end{array}$ & $\begin{array}{l}\text { Sepsis }(4.2 \%) \text {, } \\
\text { small bowel } \\
\text { bacterial } \\
\text { overgrowth } \\
(4.2 \%)\end{array}$ & $\begin{array}{l}\text { Colonoscopy } \\
\& \mathrm{NJ}\end{array}$ & 8 \\
\hline $\begin{array}{l}\text { Costello, } \\
2019[22]\end{array}$ & UC & 69 & 38.5 & $45.2 \%$ & 31 & $\begin{array}{l}\text { Worsening } \\
\text { colitis } \\
(21 \%)\end{array}$ & $\begin{array}{l}\text { Worsening } \\
\text { colitis (4.3\%), } \\
\text { pneumonia } \\
(1.4 \%), \text { rCDI } \\
\text { requiring } \\
\text { colectomy } \\
(1.4 \%)\end{array}$ & Colonoscopy & 8 \\
\hline $\begin{array}{l}\text { Halkjær, } \\
2018 \text { [52] }\end{array}$ & IBS & 26 & 37.3 & $68 \%$ & 22 & $\begin{array}{l}\text { Nausea } \\
\text { \& emesis } \\
(35 \%)\end{array}$ & None & Capsule & 24 \\
\hline $\begin{array}{l}\text { Johnsen, } \\
2017 \text { [23] }\end{array}$ & IBS & 55 & 44 & $65 \%$ & 3 & $\begin{array}{l}\text { Abdominal } \\
\text { pain }(5 \%)\end{array}$ & None & Colonoscopy & 52 \\
\hline Каo, 2017 [53] & rCDI & 112 & 58.7 & $70.5 \%$ & 12 & $\begin{array}{l}\text { Abdominal } \\
\text { pain }(5 \%)\end{array}$ & None & $\begin{array}{l}\text { Colonoscopy } \\
\text { \& Capsule }\end{array}$ & 12 \\
\hline $\begin{array}{l}\text { Moayyedi, } \\
2015 \text { [17] }\end{array}$ & UC & 38 & 42.4 & $53 \%$ & 3 & $\begin{array}{l}\text { Worsening } \\
\text { Colitis } \\
(8 \%)\end{array}$ & $\begin{array}{l}\text { Patchy colitis } \\
\text { \& rectal } \\
\text { abscess }(5.3 \%) \text {, } \\
\text { CDI }(2.6 \%)\end{array}$ & Enema & 7 \\
\hline $\begin{array}{l}\text { Rossen, } \\
2015 \text { [9] }\end{array}$ & UC & $23^{\prime}$ & 40.5 & $54.1 \%$ & 18 & $\begin{array}{l}\text { Bloating } \\
(59 \%)\end{array}$ & None & Enteroscopy & 12 \\
\hline $\begin{array}{l}\text { Youngster, } \\
2014 \text { [54] }\end{array}$ & rCDI & 20 & 54.5 & $55 \%$ & 5 & $\begin{array}{l}\text { Bloating } \\
(20 \%)\end{array}$ & None & $\begin{array}{l}\text { Colonoscopy } \\
\& \text { NGT }\end{array}$ & 24 \\
\hline
\end{tabular}

MRDO, multidrug resistant organism; $r C D I$, recurrent Clostridium difficile infection; SAE, serious adverse events; $A E$, adverse events,

$N G T$, nasogastric tube; NJ, nasojejunal tube; IBS, irritable bowel syndrome; UC, ulcerative colitis

during the follow-up period. The reported SAE rates ranged from $0-7.3 \%$. There was little heterogeneity observed $(\mathrm{Q}=7.7$, $\left.I^{2}=0, \tau^{2}=0\right)$. The pooled rate of SAE was calculated at $5.3 \%$ (95\%CI 0.031-0.088; 2-sided $\mathrm{P}<0.001$ ). A forest plot of pooled $\mathrm{SAE}$ rates can be seen in Fig. 3. The most common SAE was C. difficile infection, reported in 3 of the 388 patients (0.8\%). A list of SAE can be seen in Table 2. No deaths attributed to FMT were reported in these 9 studies. A detailed description of causes of death can be seen in Table 3 .

\section{Impact of covariates on AE}

We hypothesized that the method of delivery may be correlated with the rate of $\mathrm{AE}$. To test that, we decided to perform a meta-regression analysis of the 9 studies selected for final inclusion. We divided the mode of delivery into 4 groups: Upper GI (nasoduodenal tube), Capsules, Lower GI (colonoscopy and enemas), and Mixed (more than a single method used in the same study). We excluded the Mixed group from the analysis to avoid confounding the results and used Lower GI as the reference group, as that is the method most commonly performed in clinical practice. Five studies were included in this model. Both the Capsules (coefficient=3.3, 95\%CI 1.08-5.64; $\mathrm{P}=0.0039$ ) and Upper GI (coefficient=2.9, 95\%CI 0.69-5. 19; $\mathrm{P}=0.01$ ) groups were associated with more total AE than the Lower GI group. This model explained $76 \%$ of the between-study variance with an $\mathrm{R}^{2}$ value of 0.76 . $\mathrm{A}$ regression figure with the logit $\mathrm{AE}$ rates in relation to delivery can be seen in Fig. 4. No other covariates were found to be associated with a difference in $\mathrm{AE}$ rates.

We attempted a meta-regression with regard to SAE rates and delivery method, but the models were underpowered to explain the variance between the groups. Thus, we decided to expand our analysis to the 60 studies included in the preliminary selection to attempt to identify risk factors associated with higher SAE rates. 
Table 2 Description of adverse events of fecal microbiota transplantation

\begin{tabular}{|c|c|}
\hline Adverse events & $\begin{array}{r}\text { Total number of } \\
\text { patients }(\mathrm{N}=388)\end{array}$ \\
\hline Abdominal pain & $23(5.93 \%)$ \\
\hline Diarrhea & $20(5.16 \%)$ \\
\hline Nausea & $18(4.64 \%)$ \\
\hline Bloating & $15(3.87 \%)$ \\
\hline Worsening colitis & $13(3.35 \%)$ \\
\hline Weight gain & $13(3.35 \%)$ \\
\hline Vomiting & $9(2.32 \%)$ \\
\hline Weight loss & $8(2.10 \%)$ \\
\hline Headache & $8(2.10 \%)$ \\
\hline Fever & $6(1.55 \%)$ \\
\hline Flatulence & $4(1.03 \%)$ \\
\hline Fecal incontinence & $4(1.03 \%)$ \\
\hline Dizziness & $4(1.03 \%)$ \\
\hline ALT elevation & $4(1.03 \%)$ \\
\hline Anemia & $3(0.77 \%)$ \\
\hline Obstipation & $3(0.77 \%)$ \\
\hline Constipation & $2(0.52 \%)$ \\
\hline Alkaline phosphatase increase & $2(0.52 \%)$ \\
\hline Reflux & $2(0.52 \%)$ \\
\hline Small bowel bacterial overgrowth & $1(0.26 \%)$ \\
\hline Fatigue & $1(0.26 \%)$ \\
\hline Serious adverse events & $\begin{array}{r}\text { Total number of } \\
\text { patients }(\mathrm{N}=388)\end{array}$ \\
\hline Clostridium difficile infection & $3(0.77 \%)$ \\
\hline Rectal abscess & $2(0.52 \%)$ \\
\hline $\begin{array}{l}\text { Patchy colonic inflammation in ulcerative } \\
\text { colitis }\end{array}$ & $2(0.52 \%)$ \\
\hline Pneumonia & $1(0.26 \%)$ \\
\hline Systemic inflammatory response syndrome & $1(0.26 \%)$ \\
\hline Hepatic encephalopathy exacerbation & $1(0.26 \%)$ \\
\hline Small intestinal bacterial overgrowth & $1(0.26 \%)$ \\
\hline
\end{tabular}

ALT, alanine aminotransferase

\section{Expanded analysis}

Weperformedanadditionalanalysisthatincludedall60studies of the preliminary selection [7-9,14-17,22,23,50-54,59-104]. Those described 3595 FMTs performed in 2921 patients with a mean age of $58 \pm 13.3$ years, of whom $60 \pm 16 \%$ were female. Mean duration of follow up was $18.9 \pm 18.8$ weeks. As was the case with the final inclusion studies, very few authors utilized some standardized guideline of AE reporting. Only 6/60 studies used the CTCAE [54,60,72,74,85,97] and Hvas et al [51] used guidelines published by the European Commission. Indications were rCDI in 42/60 studies, UC in 7/60, Crohn's disease
Table 3 Deaths described in the included studies

\begin{tabular}{|c|c|c|}
\hline Cause of death & $(\mathrm{N}=6)$ & $\begin{array}{l}\text { Related } \\
\text { to FMT? }\end{array}$ \\
\hline Unspecified cardiopulmonary disease & 2 & No \\
\hline Malignancy & 3 & No \\
\hline COPD exacerbation & 1 & No \\
\hline Deaths in supplemental studies & $(\mathrm{N}=89)$ & $\begin{array}{l}\text { Related } \\
\text { to FMT? }\end{array}$ \\
\hline Unspecified causes & 54 & No \\
\hline Malignancy & 7 & No \\
\hline Worsening Clostridium difficile infection & 6 & No \\
\hline Aspiration pneumonia & 4 & Yes \\
\hline Pneumonia & 4 & No \\
\hline Chronic obstructive pulmonary disease & 2 & No \\
\hline Cerebrovascular accident & 2 & No \\
\hline Pre-existing sepsis & 2 & No \\
\hline Urosepsis & 2 & No \\
\hline Concussion due to traumatic fall & 1 & No \\
\hline Pulmonary embolism & 1 & No \\
\hline Renal failure & 1 & No \\
\hline Arterial thrombus & 1 & No \\
\hline Chronic respiratory failure & 1 & No \\
\hline Complications due to hemodialysis & 1 & No \\
\hline
\end{tabular}

FMT, fecal microbiota transplantation; COPD, chronic obstructive pulmonary disease

in $3 / 60$, IBS in $3 / 60$, metabolic syndrome in $2 / 60$, MDRO colonization in $1 / 60$, and mixed indication in $2 / 60$. The mode of delivery varied, with 5/60 using capsules, 10/60 some method of esophagogastroduodenoscopy or nasogastric/ nasoenteric tube delivery (Upper GI group), 23/60 colonoscopy or enema (Lower GI group), and the remaining 22/60 using various method of delivery (Mixed group). Heterogeneity in rates of SAE was low, with $I^{2}=0 \%$. The pooled rate of SAE was calculated at 3.0\% (95\%CI 0.0171-0.0505; 2-sided $\mathrm{P}<0.001)$. We performed analyses of subgroups by indication and delivery method. Patients with Crohn's disease had the lowest point estimate of SAE rate, at $1.3 \%$ (95\%CI $0.0027-0.064 ; 2$-sided $\mathrm{P}=0.001)$, and patients with $\mathrm{UC}$ had the highest, at $5.3 \%$ (95\%CI 0.0293-0.0952; 2-sided $\mathrm{P}=0.001$ ). In terms of delivery method, the Lower GI delivery subgroup had the highest SAE rate point estimate at $4.3 \%(95 \% \mathrm{CI} 0.0302-0.0620 ; 2$-sided $\mathrm{P}=0.001)$ and the Upper GI delivery subgroup had the lowest SAE rate point estimate at $1.5 \%(95 \%$ CI $0.0063-0.0334 ; 2$-sided $\mathrm{P}=0.001)$.

To identify independent predictors of SAE development, we performed a meta-regression analysis on 26 of the studies that had complete data available for the covariates assessed. The optimal model included the mode of delivery (with the Mixed group removed), follow up in weeks and percentage of females as covariates. This model explained $85 \%$ of the between-study variance, with an $\mathrm{R}^{2}$ value of 0.85 . Interestingly, the only factor 


\begin{tabular}{|c|c|c|c|c|c|c|c|c|c|}
\hline \multirow[t]{2}{*}{ Study name } & & & & & \multicolumn{5}{|c|}{ Event rate and $95 \% \mathrm{Cl}$} \\
\hline & $\begin{array}{l}\text { Event } \\
\text { rate }\end{array}$ & Total & $\begin{array}{l}\text { Lower } \\
\text { limit }\end{array}$ & $\begin{array}{c}\text { Upper } \\
\text { limit }\end{array}$ & $p$-Value & & & & \\
\hline Huttner & 0.048 & $1 / 21$ & 0.007 & 0.271 & 0.003 & 1 & & & 1 \\
\hline Hvas & 0.083 & $2 / 24$ & 0.021 & 0.279 & 0.001 & & & & \\
\hline Costello & 0.072 & $5 / 69$ & 0.030 & 0.163 & 0.000 & & & & \\
\hline Halkjaer & 0.019 & $0 / 26$ & 0.001 & 0.236 & 0.005 & & & & \\
\hline Johnsen & 0.009 & $0 / 55$ & 0.001 & 0.127 & 0.001 & & & & \\
\hline Kao & 0.004 & $0 / 112$ & 0.000 & 0.067 & 0.000 & & & & \\
\hline Moayyedi & 0.079 & $3 / 38$ & 0.026 & 0.218 & 0.000 & & & & \\
\hline Rossen & 0.021 & $0 / 23$ & 0.001 & 0.259 & 0.007 & & & & \\
\hline Youngster & 0.024 & $0 / 20$ & 0.001 & 0.287 & 0.009 & & & & \\
\hline & 0.053 & & 0.031 & 0.088 & 0.000 & & & & \\
\hline & & & & & -0.50 & -0.25 & 0.00 & 0.25 & 0.50 \\
\hline
\end{tabular}

Figure 3 Forest plot of serious adverse event rate CI, confidence interval

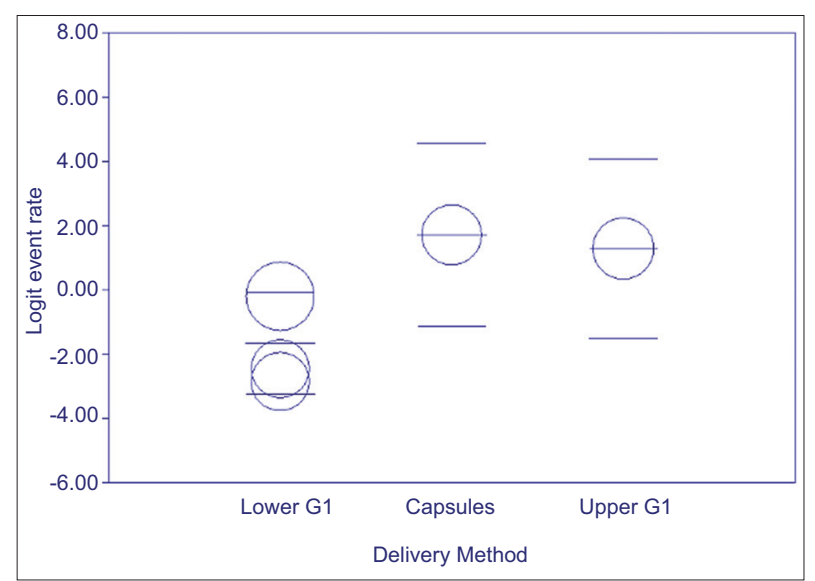

Figure 4 Regression analysis of impact of delivery method on logit of total adverse event rate

${ }^{*}$ Based on data of from 5 studies from included in the original analysis G1, gastrointestinal

independently associated with lower SAE rates was an Upper GI method of delivery (coefficient=-1.4, 95\%CI -2.37-0.92; $\mathrm{P}=0.02$ ). There was a trend toward lower rates of SAE as the percentage of female patients increased that did not reach statistical significance $(\mathrm{P}=0.056)$. Duration of follow up was not independently associated with SAE rates, neither was FMT indication in separate analysis. Fig. 5 depicts logit SAE rates in relation to delivery method and Fig. 6 depicts logit SAE rates in relation to the percentage of female subjects.

\section{Discussion}

The primary goal of our meta-analysis was to obtain accurate estimates of the total rates of AE and SAE after FMT. All the studies selected for final inclusion were prospective, randomized controlled trials with rigorous methodology and a low risk of bias, based on a validated assessment tool [46]. Some of the studies were blinded $[9,17,22,23,52]$. Furthermore, they all included a fairly large number of subjects $(n \geq 20)$, encompassed a broad age range, had a wide array of FMT indications and included all the different modes of FMT delivery. We consider that this study selection adds to the strength of our analysis.

We found the pooled AE of FMT to be $39.3 \%$, with a wide $\mathrm{CI}$ and significant heterogeneity between different studies. We believe this wide variability stems from the different methods authors used to capture $\mathrm{AE}$ and different definitions of relatedness of an $\mathrm{AE}$ to the procedure. The vast majority of AE recorded were mild and self-limited, such as abdominal pain, bloating, nausea and vomiting. The reason abdominal pain was the most commonly reported AE is unknown. Details on the severity of pain were not reported by authors and it should be noted that pain scales are subjective. It is possible that pain or other effects, such as nausea, could be related to the procedures, such as colonoscopy, as opposed to the effect of the microbiota. Four studies did describe rates of AE in the placebo arm $[9,17,23,50,52]$. For example, Halkjaer et al reported an AE rate of $57.7 \%$ in the placebo group and the only AE significantly more common in the intervention group was diarrhea. Overall, of the 135 patients in the placebo arms, 49 developed AE (36.3\%), and 4 had SAE (2.96\%). The differences in AE and SAE rates between both arms were not statistically significant.

The pooled rate of SAE was calculated at 5.3\%, with a narrow $\mathrm{CI}$ and low heterogeneity, and probably represents a more accurate estimate than total AE rate. Despite the high quality of the studies, few authors followed specific criteria to determine the seriousness of AE. Again, it should be noted that AE and SAE were included in the analysis only if deemed related or possibly related to FMT by the authors, but the criteria for that decision were mostly unclear. In general, the SAE rates appeared similar between both study arms. For example, in the study by Moayeddi et al [17] there was no difference in SAE rates between the FMT and control groups. 


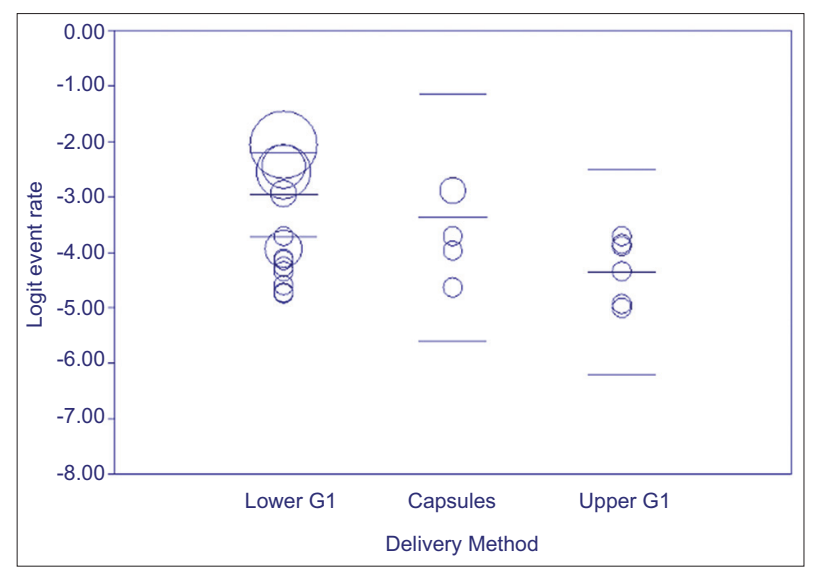

Figure 5 Regression analysis of impact of delivery method on logit of serious adverse event rate*

${ }^{*}$ Based on 26 studies from the expanded analysis G1, gastrointestinal

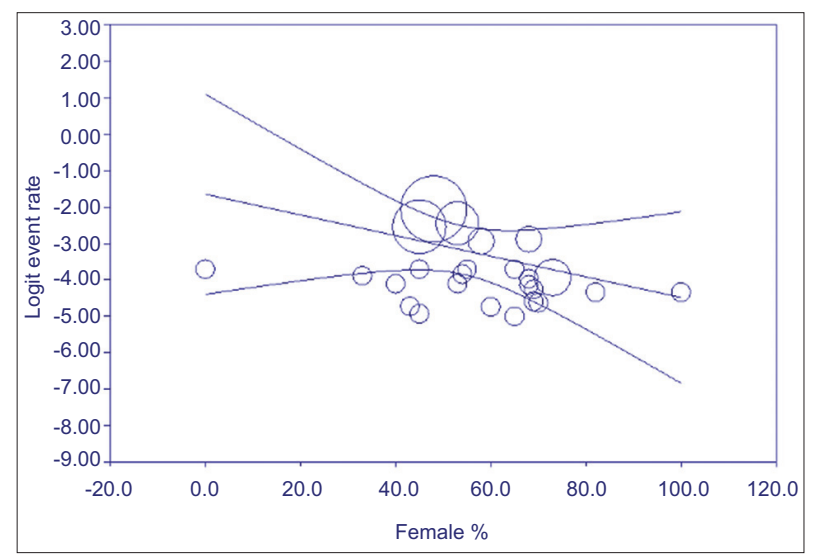

Figure 6 Regression analysis of impact of patient gender on logit of serious adverse event rate ${ }^{\star}$

${ }^{\star}$ Based on 26 studies from the expanded analysis

Our secondary objective was to attempt to identify risk factors for AE development. Among the 9 studies finally included, it appeared that upper GI delivery through capsules or nasoduodenal tube was associated with a higher rate of $\mathrm{AE}$ development. No other covariates were significantly associated with different $\mathrm{AE}$ rates in regression analysis. A possible explanation for this finding is that sedation during colonoscopy minimizes patient perception and reporting of the mild, selflimited $\mathrm{AE}$ of the procedure.

We also performed a more expanded analysis of 60 studies to attempt to identify risk factors for development of SAE. Results of this analysis should be considered less accurate, as the included studies had lower overall quality, a higher risk of bias and it could not be determined whether there might be some duplicate reporting of cases. Interestingly, upper GI delivery (excluding capsules) was the only risk factor independently associated with a lower rate of SAE.

One of the main concerns regarding the use of FMT is the possible transmission of infectious diseases. Since the earliest studies [1], rigorous donor screening and testing has been proposed to minimize that risk. In 2019, the FDA raised alarm by issuing a series of safety communications describing the cases of 2 immunocompromised adults who developed infection with extended-spectrum $\beta$-lactamase-producing $E$. coli after receiving FMT prepared with stool from the same donor-one of the patients died [44]. As a result, the FDA now recommends MDRO testing and exclusion of persons at risk of MDRO carriage (such as healthcare workers) from donating stool. Few infectious complications characterized as SAE occurred in the 9 series of our analysis; those can be seen in Table 1. The biggest theoretical concern involves immunocompromised patients, although the use of FMT has been shown to be relatively safe in this group, in both case reports [105-107] and cohort studies $[98,108,109]$. That includes patients with cirrhosis $[110,111]$. There is also theoretical concern that FMT will promote the transfer of donor viral communities that could cause infectious or immunologic complications in the recipient. Norovirus gastroenteritis after FMT has been reported [112]. Chehoud et al [113] demonstrated transfer of viral communities with FMT, but no viruses pathogenic to humans were found to be transferred. Other studies have linked virome changes with treatment response [114,115]. More studies are needed before conclusions can be drawn about the clinical impact of viral community transfer with FMT. The emergence of the novel coronavirus, which has been documented to be present in stool $[116,117]$, has added safety concerns to FMT and complicated the workflow of stool donation and FMT research [118]. All of the studies included in our analysis preceded the emergence of the disease. Finally, it has been postulated that autologous FMT may have decreased infectious risks [55]. Thirty-four patients who received autologous FMT were included in one of the examined studies [22]. Rossen et al [9] compared duodenal infusions of donor to autologous feces and found similar AE and SAE rates between the 2 groups. Further studies are needed to clarify whether autologous FMT has a favorable safety profile.

Another theoretical concern of FMT revolves around long-term safety, and more specifically its ability to induce immunologically mediated complications in the host that are not initially evident. The long-term safety has been explored in several studies, with follow-up periods of about 1 year [14,119]. In our analysis, the study by Johnsen et al [52] had the longest follow up of 52 weeks. None of the participants reported any new diagnoses or lasting side-effects 1 year after FMT. Agrawal et al [14] reported new diagnoses of microscopic colitis, Sjögren syndrome, contact dermatitis, Bence-Jones proteinuria, follicular lymphoma and laryngeal cancer in patients who had FMT. However, patients had clear risk factors for some, and for others they mentioned there was no evidence for or against causation by FMT. Worsening of underlying inflammatory bowel disease post FMT has also been previously reported $[18,120,121]$, and was also seen in the studies we analyzed. Finally, there have been case reports linking FMT to obesity [122] and, interestingly, there were 13 cases of weight gain after FMT reported in the included studies. Discerning whether long-term new $\mathrm{AE}$ diagnoses are attributable to FMT poses several methodological risks. Randomized controlled trials with long follow-up duration and national FMT registries that have been recently started in 
America, China and Europe $[2,123,124]$ should help answer this difficult question in the future.

Another important question is what the estimated mortality associated with FMT is. In the 9 high-quality prospective studies no deaths were encountered. However, in the supplemental studies 4 deaths were encountered and were all periprocedural. Aspiration of fecal contents was the most common event and occurred in 3 patients, all treated using 3 different methods of upper GI administration, including via nasojejunal or nasoduodenal tube, and gastroscopy (Goldenberg, Van Beurden, Cohen). The fourth patient whose death was related to FMT aspirated during sedation prior to administration of fecal contents via colonoscopy. Based on our literature review, it appears that the highest risk for patient mortality is during sedation or administration of fecal contents via upper GI administration.

Further review of other studies not included in this review provided 3 studies in which death was potentially related to FMT, based on the authors' conclusions. One patient received FMT via a pre-existing G-tube placed for oropharyngeal malignancy, the procedure was uncomplicated, but 3 days later he developed septic shock with toxic megacolon and multiple organisms were isolated in blood cultures including E. coli and Lactobacillus casei. He underwent emergent colectomy, but unfortunately died the following day. It should be noted however, that he was being treated for $C$. difficile infection and antibiotics were immediately discontinued on the day of FMT [122]. Another study noted a death following aspiration which occurred during sedation for FMT via colonoscopy [123]. Finally, the third death occurred 48 days after regurgitation of fecal material administered via gastroscope in the distal duodenum. The patient remained hospitalized during the entire 48 days and ultimately succumbed to his pneumonia [124]. The conclusion of the third study was that administration of upper GI FMT should only be performed in awake patients; based on our findings, this may be an appropriate way to reduce procedural related mortality to FMT, but clinical context should always be taken into account when deciding whether sedation is warranted.

Our study has several limitations. Firstly, the search was limited by our terms and criteria and only included studies until August 2019. Differences between studies in duration of follow up, patient characteristics and methodology have the potential to confound the results. Follow-up duration is likely insufficient to detect long-term $\mathrm{AE}$ and the number of patients is insufficient to detect very rare AE. As with any meta-analysis there is a risk of publication bias. We cannot exclude its presence based on our analysis (see funnel plots). Our regression analysis was also limited by the small number of studies (particularly in the case of SAE) and by not being able to include all possible risk factors (for example fresh versus frozen stool preparation). Most importantly, our study is limited by the inherent methodological difficulties of $\mathrm{AE}$ reporting in RCTs $[125,126]$ and the inconsistencies in $\mathrm{AE}$ reporting among authors. This could indicate some underlying reporting/misclassification bias. We were limited to using rates of $\mathrm{AE}$ and SAE as defined by authors. Few authors adopted standardized guidelines for determining the seriousness, expectedness and relatedness of AE. This probably led to the significant heterogeneity in the total rates of AE.

In conclusion, FMT appears to be a safe treatment modality. Most AE are mild and occur in the short term. There is wide variability in reporting methodology, even among high-quality studies. The rate of SAE is estimated at $5.3 \%$ and mortality is low. Upper GI and capsule delivery were associated with lower rates of total $\mathrm{AE}$, but only capsule delivery was associated with lower SAE. Determining the relation of $\mathrm{AE}$ to the procedure is challenging, and authors should consider using standardized criteria. Longitudinal studies will be needed to determine the long-term risks.

\section{Summary Box}

\section{What is already known:}

- Fecal microbiota transplantation (FMT) is an established treatment modality for recurrent Clostridium difficile infection and has shown promise in multiple disease states

- There are safety concerns in FMT, primarily with regards to long-term risk

\section{What the new findings are:}

- FMT appears to be safe in the short to mid-term with a pooled serious adverse event rate of $5.4 \%$ based on high quality data

- Lower gastrointestinal tract delivery of FMT is correlated with a lower total adverse event rate

\section{References}

1. Bakken JS, Borody T, Brandt LJ, et al; Fecal Microbiota Transplantation Workgroup. Treating Clostridium difficile infection with fecal microbiota transplantation. Clin Gastroenterol Hepatol 2011;9:1044-1049.

2. Zhang F, Cui B, He X, Nie Y, Wu K, Fan D. Microbiota transplantation: concept, methodology and strategy for its modernization. Protein Cell 2018;9:462-473.

3. Nurmi E, Rantala M. New aspects of Salmonella infection in broiler production. Nature 1973;241:210-211.

4. Eiseman B, Silen W, Bascom GS, Kauvar AJ. Fecal enema as an adjunct in the treatment of pseudomembranous enterocolitis. Surgery 1958;44:854-859.

5. Schwan A, Sjölin S, Trottestam U, Aronsson B. Relapsing Clostridium difficile enterocolitis cured by rectal infusion of normal faeces. Scand J Infect Dis 1984;16:211-215.

6. van Nood E, Vrieze A, Nieuwdorp M, et al. Duodenal infusion of donor feces for recurrent Clostridium difficile. $N$ Engl J Med 2013;368:407-415.

7. Mattila E, Uusitalo-Seppälä R, Wuorela $M$, et al. Fecal transplantation, through colonoscopy, is effective therapy for recurrent Clostridium difficile infection. Gastroenterology 2012;142:490-496.

8. Brandt LJ, Aroniadis OC, Mellow M, et al. Long-term follow-up of 
colonoscopic fecal microbiota transplant for recurrent Clostridium difficile infection. Am J Gastroenterol 2012;107:1079-1087.

9. Rossen NG, Fuentes S, van der Spek MJ, et al. Findings from a randomized controlled trial of fecal transplantation for patients with ulcerative colitis. Gastroenterology 2015;149:110-118.

10. Cammarota G, Ianiro G, Gasbarrini A. Fecal microbiota transplantation for the treatment of Clostridium difficile infection: a systematic review. J Clin Gastroenterol 2014;48:693-702.

11. Baro E, Galperine T, Denies F, et al. Cost-effectiveness analysis of five competing strategies for the management of multiple recurrent community-onset Clostridium difficile infection in France. PLoS One 2017;12:e0170258.

12. Abdali ZI, Roberts TE, Barton P, Hawkey PM. Economic evaluation of faecal microbiota transplantation compared to antibiotics for the treatment of recurrent Clostridioides difficile infection. EClinicalMedicine 2020;24:100420.

13. Varier RU, Biltaji E, Smith KJ, et al. Cost-effectiveness analysis of treatment strategies for initial Clostridium difficile infection. Clin Microbiol Infect 2014;20:1343-1351.

14. Agrawal M, Aroniadis OC, Brandt LJ, et al. The long-term efficacy and safety of fecal microbiota transplant for recurrent, severe, and complicated Clostridium difficile infection in 146 elderly individuals. J Clin Gastroenterol 2016;50:403-407.

15. Khan MA, Sofi AA, Ahmad U, et al. Efficacy and safety of, and patient satisfaction with, colonoscopic-administered fecal microbiota transplantation in relapsing and refractory community- and hospital-acquired Clostridium difficile infection. Can J Gastroenterol Hepatol 2014;28:434-438.

16. Jiang ZD, Jenq RR, Ajami NJ, et al. Safety and preliminary efficacy of orally administered lyophilized fecal microbiota product compared with frozen product given by enema for recurrent Clostridium difficile infection: A randomized clinical trial. PLoS One 2018;13:e205064.

17. Moayyedi P, Surette MG, Kim PT, et al. Fecal microbiota transplantation induces remission in patients with active ulcerative colitis in a randomized controlled trial. Gastroenterology 2015; 149:102-109

18. Suskind DL, Brittnacher MJ, Wahbeh G, et al. Fecal microbial transplant effect on clinical outcomes and fecal microbiome in active Crohn's disease. Inflamm Bowel Dis 2015;21:556-563.

19. Vaughn BP, Vatanen T, Allegretti JR, et al. Increased intestinal microbial diversity following fecal microbiota transplant for active Crohn's disease. Inflamm Bowel Dis 2016;22:2182-2190.

20. Narula N, Kassam Z, Yuan Y, et al. Systematic review and metaanalysis: fecal microbiota transplantation for treatment of active ulcerative colitis. Inflamm Bowel Dis 2017;23:1702-1709.

21. Wang H, Cui B, Li Q, et al. The safety of fecal microbiota transplantation for Ccrohn's disease: findings from a long-term study. Adv Ther 2018;35:1935-1944.

22. Costello SP, Hughes PA, Waters O, et al. Effect of fecal microbiota transplantation on 8-week remission in patients with ulcerative colitis: a randomized clinical trial. JAMA 2019;321:156-164.

23. Johnsen PH, Hilpüsch F, Cavanagh JP, et al. Faecal microbiota transplantation versus placebo for moderate-to-severe irritable bowel syndrome: a double-blind, randomised, placebo-controlled, parallel-group, single-centre trial. Lancet Gastroenterol Hepatol 2018;3:17-24.

24. Aroniadis OC, Brandt LJ, Oneto C, et al. Faecal microbiota transplantation for diarrhoea-predominant irritable bowel syndrome: a double-blind, randomised, placebo-controlled trial. Lancet Gastroenterol Hepatol 2019;4:675-685.

25. Mazzawi T, Hausken T, Hov JR, et al. Clinical response to fecal microbiota transplantation in patients with diarrhea-predominant irritable bowel syndrome is associated with normalization of fecal microbiota composition and short-chain fatty acid levels. Scand J
Gastroenterol 2019;54:690-699

26. Johnsen PH, Hilpüsch F, Valle PC, Goll R. The effect of fecal microbiota transplantation on IBS related quality of life and fatigue in moderate to severe non-constipated irritable bowel: Secondary endpoints of a double blind, randomized, placebo-controlled trial. EBioMedicine 2020;51:102562.

27. Yu EW, Gao L, Stastka P, et al. Fecal microbiota transplantation for the improvement of metabolism in obesity: The FMTTRIM double-blind placebo-controlled pilot trial. PLoS Med 2020;17:e1003051.

28. Vrieze A, Van Nood E, Holleman F, et al. Transfer of intestinal microbiota from lean donors increases insulin sensitivity in individuals with metabolic syndrome. Gastroenterology 2012;143:913-916.

29. Yoon YK, Suh JW, Kang EJ, Kim JY. Efficacy and safety of fecal microbiota transplantation for decolonization of intestinal multidrug-resistant microorganism carriage: beyond Clostridioides difficile infection. Ann Med 2019;51:379-389.

30. Tian H, Ge X, Nie Y, et al. Fecal microbiota transplantation in patients with slow-transit constipation: A randomized, clinical trial. PLoS One 2017;12:e171308.

31. Bajaj JS, Kassam Z, Fagan A, et al. Fecal microbiota transplant from a rational stool donor improves hepatic encephalopathy: A randomized clinical trial. Hepatology 2017;66:1727-1738.

32. Selvig D, Piceno Y, Terdiman J, et al. Fecal microbiota transplantation in pouchitis: clinical, endoscopic, histologic, and microbiota results from a pilot study. Dig Dis Sci 2020;65:10991106.

33. Allegretti JR, Kassam Z, Carrellas M, et al. Fecal microbiota transplantation in patients with primary sclerosing cholangitis: a pilot clinical trial. Am J Gastroenterol 2019;114:1071-1079.

34. Wang Y, Wiesnoski DH, Helmink BA, et al. Fecal microbiota transplantation for refractory immune checkpoint inhibitorassociated colitis. Nat Med 2018;24:1804-1808.

35. Prochazkova P, Roubalova R, Dvorak J, et al. Microbiota, microbial metabolites, and barrier function in a patient with anorexia nervosa after fecal microbiota transplantation. Microorganisms 2019;7:338.

36. de Clercq NC, Frissen MN, Davids M, Groen AK, Nieuwdorp M. Weight gain after fecal microbiota transplantation in a patient with recurrent underweight following clinical recovery from anorexia nervosa. Psychother Psychosom 2019;88:58-60.

37. Borody T, Leis S, Campbell J, Torres M, Nowak A. Fecal microbiota transplantation (FMT) in multiple sclerosis (MS) 942. Am J Gastroenterol 2011;106:S352

38. Kang DW, Adams JB, Gregory AC, et al. Microbiota transfer therapy alters gut ecosystem and improves gastrointestinal and autism symptoms: an open-label study. Microbiome 2017;5:10.

39. Li Q, Wang C, Tang C, et al. Successful treatment of severe sepsis and diarrhea after vagotomy utilizing fecal microbiota transplantation: a case report. Crit Care 2015;19:37.

40. Bakker GJ, Nieuwdorp M. Fecal microbiota transplantation: therapeutic potential for a multitude of diseases beyond Clostridium difficile. Microbiol Spectr 2017;5.

41. Iqbal U, Anwar H, Karim MA. Safety and efficacy of encapsulated fecal microbiota transplantation for recurrent Clostridium difficile infection: a systematic review. Eur J Gastroenterol Hepatol 2018;30:730-734.

42. Baxter M, Ahmad T, Colville A, Sheridan R. Fatal aspiration pneumonia as a complication of fecal microbiota transplant. Clin Infect Dis 2015;61:136-137.

43. Baxter M, Colville A. Adverse events in faecal microbiota transplant: a review of the literature. J Hosp Infect 2016;92:117-127.

44. FDA. Important safety alert regarding use of fecal microbiota for transplantation and risk of serious adverse reactions due to transmission of multi-drug resistant organisms. U.S. Food \& Drug 
Administration, June 13, 2019.

45. National Institutes of Health. Common terminology criteria for adverse events (CTCAE) v5.0. NIH, National Cancer Institute, November 27, 2017.

46. Sterne JAC, Savović J, Page MJ, et al. RoB 2: a revised tool for assessing risk of bias in randomised trials. BMJ 2019;366:14898.

47. Higgins JP, Thompson SG. Quantifying heterogeneity in a metaanalysis. Stat Med 2002;21:1539-1558.

48. Higgins JP, Thompson SG, Deeks JJ, Altman DG. Measuring inconsistency in meta-analyses. BMJ 2003;327:557-560.

49. Hozo SP, Djulbegovic B, Hozo I. Estimating the mean and variance from the median, range, and the size of a sample. BMC Med Res Methodol 2005;5:13.

50. Huttner BD, de Lastours V, Wassenberg M, et al; R-Gnosis WP3 study group. A 5-day course of oral antibiotics followed by faecal transplantation to eradicate carriage of multidrug-resistant Enterobacteriaceae: a randomized clinical trial. Clin Microbiol Infect 2019;25:830-838.

51. Hvas CL, Dahl Jorgensen SM, Jorgensen SP, et al. Fecal microbiota transplantation is superior to fidaxomicin for treatment of recurrent Clostridium difficile infection. Gastroenterology 2019;156:13241332.

52. Halkjær SI, Christensen AH, Lo BZS, et al. Faecal microbiota transplantation alters gut microbiota in patients with irritable bowel syndrome: results from a randomised, double-blind placebocontrolled study. Gut 2018;67:2107-2115.

53. Kao D, Roach B, Silva M, et al. Effect of oral capsule- vs colonoscopy-delivered fecal microbiota transplantation on recurrent Clostridium difficile infection: a randomized clinical trial. JAMA 2017;318:1985-1993.

54. Youngster I, Sauk J, Pindar C, et al. Fecal microbiota transplant for relapsing Clostridium difficile infection using a frozen inoculum from unrelated donors: a randomized, open-label, controlled pilot study. Clin Infect Dis 2014;58:1515-1522.

55. Basson AR, Zhou Y, Seo B, Rodriguez-Palacios A, Cominelli F. Autologous fecal microbiota transplantation for the treatment of inflammatory bowel disease. Transl Res 2020;226:1-11.

56. Detailed guidance on the collection, verification and presentation of adverse event/reaction reports arising from clinical trials on medicinal products for human use ('CT-3'). CELEX number 52011XC0611(01).

57. Trotti A, Colevas AD, Setser A, et al. CTCAE v3.0: development of a comprehensive grading system for the adverse effects of cancer treatment. Semin Radiat Oncol 2003;13:176-181.

58. U.S. Food and Drug Administration 21CFR314.80. Code of Federal Regulations: FDA, April 1, 2019.

59. Yang $\mathrm{Z}, \mathrm{Bu} \mathrm{C}$, Yuan $\mathrm{W}$, et al. Fecal microbiota transplant via endoscopic delivering through small intestine and colon: no difference for Crohn's disease. Dig Dis Sci 2020;65:150-157.

60. Nowak A, Hedenstierna M, Ursing J, Lidman C, Nowak P. Efficacy of routine fecal microbiota transplantation for treatment of recurrent Clostridium difficile infection: a retrospective cohort study. Int J Microbiol 2019;2019:7395127.

61. Tian Y, Zhou Y, Huang S, et al. Fecal microbiota transplantation for ulcerative colitis: a prospective clinical study. BMC Gastroenterol 2019;19:116

62. Lui RN, Wong SH, Lau LHS, et al. Faecal microbiota transplantation for treatment of recurrent or refractory Clostridioides difficile infection in Hong Kong. Hong Kong Med J 2019;25:178-182.

63. Kim KO, Schwartz MA, Lin OST, Chiorean MV, Gluck M. Reducing cost and complexity of fecal microbiota transplantation using universal donors for recurrent Clostridium difficile infection. Adv Ther 2019;36:2052-2061.

64. Huang HL, Chen HT, Luo QL, et al. Relief of irritable bowel syndrome by fecal microbiota transplantation is associated with changes in diversity and composition of the gut microbiota. J Dig Dis 2019;20:401-408.

65. Allegretti JR, Kassam Z, Fischer M, Kelly C, Chan WW. Risk factors for gastrointestinal symptoms following successful eradication of Clostridium difficile by fecal microbiota transplantation (FMT). J Clin Gastroenterol 2019;53:e405-e408.

66. Greenberg SA, Youngster I, Cohen NA, et al. Five years of fecal microbiota transplantation - an update of the Israeli experience. World J Gastroenterol 2018;24:5403-5414.

67. Vigvári S, Vincze, Solt J, et al. Experiences with fecal microbiota transplantation in Clostridium difficile infections via upper gastrointestinal tract. Acta Microbiol Immunol Hung 2019;66:179-188.

68. Allegretti JR, Fischer M, Sagi SV, et al. Correction to: Fecal microbiota transplantation capsules with targeted colonic versus gastric delivery in recurrent Clostridium difficile infection: a comparative cohort analysis of high and low dose. Dig Dis Sci 2019;64:2059.

69. Duarte-Chavez R, Wojda TR, Zanders TB, Geme B, Fioravanti G, Stawicki SP. Early results of fecal microbial transplantation protocol implementation at a community-based university hospital. J Glob Infect Dis 2018;10:47-57.

70. Ponte A, Pinho R, Mota M, et al. Fecal microbiota transplantation in refractory or recurrent Clostridium difficile infection: a reallife experience in a non-academic center. Rev Esp Enferm Dig 2018;110:311-315.

71. Smits LP, Kootte RS, Levin E, et al. Effect of vegan fecal microbiota transplantation on carnitine- and choline-derived trimethylamine$\mathrm{N}$-oxide production and vascular inflammation in patients with metabolic syndrome. J Am Heart Assoc 2018;7:e008342

72. Mintz M, Khair S, Grewal S, et al. Longitudinal microbiome analysis of single donor fecal microbiota transplantation in patients with recurrent Clostridium difficile infection and/or ulcerative colitis. PLoS One 2018;13:e190997.

73. Goldenberg SD, Batra R, Beales I, et al. Comparison of different strategies for providing fecal microbiota transplantation to treat patients with recurrent Clostridium difficile infection in two English hospitals: a review. Infect Dis Ther 2018;7:71-86.

74. Li P, Zhang T, Xiao Y, et al. Timing for the second fecal microbiota transplantation to maintain the long-term benefit from the first treatment for Crohn's disease. Appl Microbiol Biotechnol 2019;103:349-360.

75. Lee S, Drennan K, Simons G, et al. The 'ins and outs' of faecal microbiota transplant for recurrent Clostridium difficile diarrhoea at Wits Donald Gordon Medical Centre, Johannesburg, South Africa. S Afr Med J 2018;108:403-407.

76. Uygun A, Ozturk K, Demirci $\mathrm{H}$, et al. Fecal microbiota transplantation is a rescue treatment modality for refractory ulcerative colitis. Medicine (Baltimore) 2017;96:e6479.

77. He Z, Li P, Zhu J, et al. Multiple fresh fecal microbiota transplants induces and maintains clinical remission in Crohn's disease complicated with inflammatory mass. Sci Rep 2017;7:4753.

78. van Beurden YH, de Groot PF, van Nood E, Nieuwdorp M, Keller JJ, Goorhuis A. Complications, effectiveness, and long term follow-up of fecal microbiota transfer by nasoduodenal tube for treatment of recurrent Clostridium difficile infection. United European Gastroenterol J 2017;5:868-879.

79. Kootte RS, Levin E, Salojärvi J, et al. Improvement of insulin sensitivity after lean donor feces in metabolic syndrome is driven by baseline intestinal microbiota composition. Cell Metab 2017;26:611-619.

80. Khanna S, Vazquez-Baeza Y, González A, et al. Changes in microbial ecology after fecal microbiota transplantation for recurrent $C$. difficile infection affected by underlying inflammatory bowel disease. Microbiome 2017;5:55.

81. Newman KM, Rank KM, Vaughn BP, Khoruts A. Treatment of 
recurrent Clostridium difficile infection using fecal microbiota transplantation in patients with inflammatory bowel disease. Gut Microbes 2017;8:303-309.

82. Nishida A, Imaeda H, Ohno M, et al. Efficacy and safety of single fecal microbiota transplantation for Japanese patients with mild to moderately active ulcerative colitis. J Gastroenterol 2017;52:476-482.

83. Wei Y, Gong J, Zhu W, et al. Pectin enhances the effect of fecal microbiota transplantation in ulcerative colitis by delaying the loss of diversity of gut flora. BMC Microbiol 2016;16:255.

84. Orenstein R, Dubberke E, Hardi R, et al; PUNCH CD Investigators. Safety and durability of RBX2660 (microbiota suspension) for recurrent Clostridium difficile infection: results of the PUNCH CD study. Clin Infect Dis 2016;62:596-602.

85. Youngster I, Mahabamunuge J, Systrom HK, et al. Oral, frozen fecal microbiota transplant (FMT) capsules for recurrent Clostridium difficile infection. BMC Med 2016;14:134.

86. Chin SM, Sauk J, Mahabamunuge J, Kaplan JL, Hohmann EL, Khalili H. Fecal microbiota transplantation for recurrent Clostridium difficile infection in patients with inflammatory bowel disease: a single-center experience. Clin Gastroenterol Hepatol 2017;15:597-599.

87. Peng Z, Xiang J, He Z, et al. Colonic transendoscopic enteral tubing: a novel way of transplanting fecal microbiota. Endosc Int Open 2016;4:E610-E613.

88. Hagel S, Fischer A, Ehlermann P, et al; German Clinical Microbiome Study Group (GCMSG). Fecal microbiota transplant in patients with recurrent Clostridium difficile infection. Dtsch Arztebl Int 2016;113:583-589.

89. Fischer M, Sipe B, Cheng YW, et al. Fecal microbiota transplant in severe and severe-complicated Clostridium difficile: a promising treatment approach. Gut Microbes 2017;8:289-302.

90. Tauxe WM, Haydek JP, Rebolledo PA, et al. Fecal microbiota transplant for Clostridium difficile infection in older adults. Therap Adv Gastroenterol 2016;9:273-281.

91. Cohen NA, Livovsky DM, Yaakobovitch S, et al. A retrospective comparison of fecal microbial transplantation methods for recurrent Clostridium difficile infection. Isr Med Assoc J 2016;18:594-599.

92. Fischer M, Kao D, Kelly C, et al. Fecal microbiota transplantation is safe and efficacious for recurrent or refractory Clostridium difficile infection in patients with inflammatory bowel disease. Inflamm Bowel Dis 2016;22:2402-2409.

93. Oprita R, Bratu M, Oprita B, Diaconescu B. Fecal transplantation - the new, inexpensive, safe, and rapidly effective approach in the treatment of gastrointestinal tract diseases. J Med Life 2016;9:160-162.

94. Mandalia A, Ward A, Tauxe W, Kraft CS, Dhere T. Fecal transplant is as effective and safe in immunocompromised as non-immunocompromised patients for Clostridium difficile. Int $J$ Colorectal Dis 2016;31:1059-1060.

95. Satokari R, Mattila E, Kainulainen V, Arkkila PE. Simple faecal preparation and efficacy of frozen inoculum in faecal microbiota transplantation for recurrent Clostridium difficile infection--an observational cohort study. Aliment Pharmacol Ther 2015;41:46-53.

96. Hirsch BE, Saraiya N, Poeth K, Schwartz RM, Epstein ME, Honig G. Effectiveness of fecal-derived microbiota transfer using orally administered capsules for recurrent Clostridium difficile infection. BMC Infect Dis 2015;15:191.

97. Youngster I, Russell GH, Pindar C, Ziv-Baran T, Sauk J, Hohmann EL. Oral, capsulized, frozen fecal microbiota transplantation for relapsing Clostridium difficile infection. JAMA 2014;312:1772-1778.

98. Kelly CR, Ihunnah C, Fischer M, et al. Fecal microbiota transplant for treatment of Clostridium difficile infection in immunocompromised patients. Am J Gastroenterol 2014;109:1065-1071.
99. Allegretti JR, Korzenik JR, Hamilton MJ. Fecal microbiota transplantation via colonoscopy for recurrent $C$. difficile infection. J Vis Exp 2014;94:52154.

100. Ray A, Smith R, Breaux J. Fecal Microbiota transplantation for Clostridium difficile infection: the Ochsner experience. Ochsner J 2014;14:538-544.

101. Rubin TA, Gessert CE, Aas J, Bakken JS. Fecal microbiome transplantation for recurrent Clostridium difficile infection: report on a case series. Anaerobe 2013;19:22-26.

102. Patel NC, Griesbach CL, DiBaise JK, Orenstein R. Fecal microbiota transplant for recurrent Clostridium difficile infection: Mayo Clinic in Arizona experience. Mayo Clin Proc 2013;88:799-805.

103. Kelly CR, de Leon L, Jasutkar N. Fecal microbiota transplantation for relapsing Clostridium difficile infection in 26 patients: methodology and results. J Clin Gastroenterol 2012;46:145-149.

104. Garborg K, Waagsbø B, Stallemo A, Matre J, Sundøy A. Results of faecal donor instillation therapy for recurrent Clostridium difficile-associated diarrhoea. Scand J Infect Dis 2010;42:857-861.

105. Ehlermann P, Dösch AO, Katus HA. Donor fecal transfer for recurrent Clostridium difficile-associated diarrhea in heart transplantation. J Heart Lung Transplantat 2014;33:551-553.

106. Friedman-Moraco RJ, Mehta AK, Lyon GM, Kraft CS. Fecal microbiota transplantation for refractory Clostridium difficile colitis in solid organ transplant recipients. Am J Transplant 2014; 14:477-480

107. Trubiano JA, George A, Barnett J, et al. A different kind of "allogeneic transplant": successful fecal microbiota transplant for recurrent and refractory Clostridium difficile infection in a patient with relapsed aggressive B-cell lymphoma. Leuk Lymphoma 2015;56:512-514.

108. Di Bella S, Gouliouris T, Petrosillo N. Fecal microbiota transplantation (FMT) for Clostridium difficile infection: focus on immunocompromised patients. J Infect Chemother 2015;21:230-237.

109. Brandt L, Aroniadis O, Greenberg A, et al. Safety of fecal microbiota transplantation (FMT) in immunocompromised (Ic) patients with inflammatory bowel disease (IBD): presidential poster: 1840. Am J Gastroenterol 2013;108:S556.

110. Bajaj JS, Fagan A, Gavis EA, Kassam Z, Sikaroodi M, Gillevet PM. Long-term outcomes of fecal microbiota transplantation in patients with cirrhosis. Gastroenterology 2019;156:1921-1923.

111. Olmedo M, Reigadas E, Valerio M, et al. Is it reasonable to perform fecal microbiota transplantation for recurrent Clostridium difficile infection in patients with liver cirrhosis? Rev Esp Quimioter 2019;32:205-207.

112. Schwartz M, Gluck M, Koon S. Norovirus gastroenteritis after fecal microbiota transplantation for treatment of Clostridium difficile infection despite asymptomatic donors and lack of sick contacts. Am J Gastroenterol 2013;108:1367.

113. Chehoud C, Dryga A, Hwang Y, et al. Transfer of viral communities between human individuals during fecal microbiota transplantation. mBio 2016;7:e00322.

114. Zuo T, Wong SH, Lam K, et al. Bacteriophage transfer during faecal microbiota transplantation in Clostridium difficile infection is associated with treatment outcome. Gut 2018;7:634-643.

115. Broecker F, Russo G, Klumpp J, Moelling K. Stable core virome despite variable microbiome after fecal transfer. Gut Microbes 2017;8:214-220.

116. Gu J, Han B, Wang J. COVID-19: gastrointestinal manifestations and potential fecal-oral transmission. Gastroenterology 2020;158:1518-1519.

117. Wang W, Xu Y, Gao R, et al. Detection of SARS-CoV-2 in different types of clinical specimens. JAMA 2020;323:1843-1844.

118. Ianiro G, Mullish BH, Kelly CR, et al. Reorganisation of faecal microbiota transplant services during the COVID-19 pandemic. Gut 2020;69:1555-1563. 
119. Ding X, Li Q, Li P, et al. Long-term safety and efficacy of fecal microbiota transplant in active ulcerative colitis. Drug Saf 2019;42:869-880.

120. Angelberger S, Reinisch W, Makristathis A, et al. Temporal bacterial community dynamics vary among ulcerative colitis patients after fecal microbiota transplantation. Am J Gastroenterol 2013;108:1620-1630.

121. De Leon LM, Watson JB, Kelly CR. Transient flare of ulcerative colitis after fecal microbiota transplantation for recurrent Clostridium difficile infection. Clin Gastroenterol Hepatol 2013;11:1036-1038.

122. Alang N, Kelly CR. Weight gain after fecal microbiota transplantation. Open Forum Infect Dis 2015;2:ofv004.

123. Kelly CR, Kim AM, Laine L, Wu GD. The AGA's fecal microbiota transplantation national registry: an important step toward understanding risks and benefits of microbiota therapeutics Gastroenterology 2017;152:681-684.

124. Perttu Lahtinen M. The finnish faecal microbiota transplantation study (FINFMT) (FINFMT). ClinicalTrials.gov Identifier: NCT03732131. November 6, 2018

125. Ioannidis JP, Contopoulos-Ioannidis DG. Reporting of safety data from randomised trials. Lancet 1998;352:1752-1753.

126. Phillips R, Hazell L, Sauzet O, Cornelius V. Analysis and reporting of adverse events in randomised controlled trials: a review. BMJ Open 2019;9:e024537.

127. Solari PR, Fairchild PG, Noa LJ, Wallace MR. Tempered enthusiasm for fecal transplant. Clin Infect Dis 2014;59:319.

128. Baxter M, Ahmad T, Colville A, Sheridan R. Fatal aspiration pneumonia as a complication of fecal microbiota transplant. Clin Infect Dis 2015;61:136-137. 